\section{Tale of a tooth}

\section{Shalini Nair, Bijesh R Nair' , Divya E}

A young adult with history of road traffic accident suffered a severe head and maxillofacial injury. The Glasgow coma scale was 8/15. He was intubated in view of his low sensorium. After one day, the ventilatory requirements progressively escalated. The $\mathrm{FiO}_{2}$ was increased from 0.3 to 0.5 for maintaining $100 \%$ saturation. Similarly, pressure requirements increased from $12 \mathrm{~cm}$ of $\mathrm{H}_{2} \mathrm{O}$ to $20 \mathrm{~cm}$ of $\mathrm{H}_{2} \mathrm{O}$ for attaining a tidal volume of $400 \mathrm{ml}$. A chest X-ray showed a lingular segmental collapse with a tooth within the bronchus. A fibreoptic bronchoscopy was carried out and the tooth was retrieved [Figure 1]. The ventilator requirements were promptly deescalated and patient was successfully extubated by the next day.

The challenges of maxillofacial injury are usually encountered at intubation. Following an uneventful intubation, suspicion of aspiration of a tooth in comatose patient is difficult because aspiration is rarely considered in the absence of an acute clinical presentation. We too had not observed the tooth in pre- and immediate post-intubation chest X-ray. Only when difficult ventilation prompted a repeat chest X-ray with a segmental collapse, we tried evaluating the cause for collapse and detected the tooth within the bronchus [Figure 2].

The possibility of such airway and pulmonary complications are twice more common when diagnosed more than 24 hours after aspiration. ${ }^{[1]}$ Extraction of

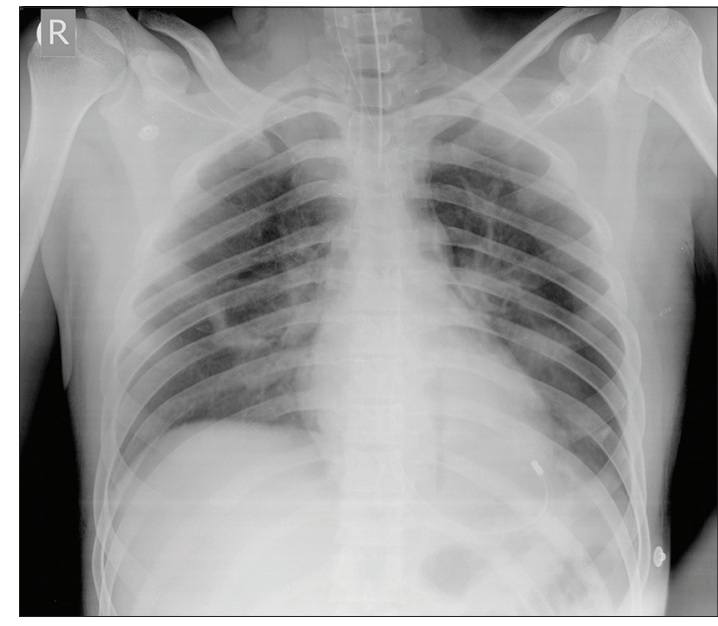

Figure 1: Chest $X$ ray showing complete expansion following bronchoscopic retrieval of the tooth

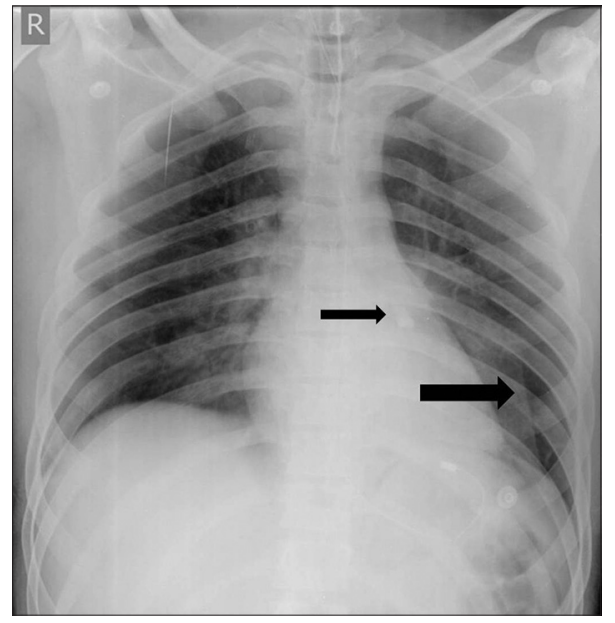

Figure 2: Chest $X$ ray showing the lingular collapse (lower arrow) caused by the tooth (upper arrow) in the left lower bronchus

Departments of Neurological Sciences, Neuro Intensive Care Unit, and ${ }^{1}$ Neurosurgery, Christian Medical College, Vellore, Tamil Nadu, India 
foreign bodies from airway is traditionally done with rigid bronchoscope.However, this was not feasible in our case due to the maxillofacial injury. Use of fibreoptic bronchoscope for the purpose is challenging, as the extraction beyond endotracheal tube may be limited due to size of the foreign body. ${ }^{[2]} \mathrm{Kim}$ et al. suggested tracheostomy as an alternative to facilitate secured airway and shorter distance for extracting foreign body associated with maxillofacial trauma. ${ }^{[3]}$

Early suspicion of an aspirated foreign body causing difficult ventilation helped us prevent a catastrophe, and timely intervention averted a morbid procedure as tracheostomy.

We, therefore, reiterate the importance of detailed scrutiny of radiograph in all comatose trauma victims for aspirated foreign bodies that can go a long way in preventing major complications.

\section{REFERENCES}

1. Esclamado RM, Richardson MA. Laryngotracheal foreign bodies in children: A comparison with bronchial foreign bodies. Am J Dis Child 1987;141:259-62.

2. Zhang M,Zhou GJ,Zhao S, Yang JX,Lu X,Gan JX, et al.Delayed diagnosis of tooth aspiration in three multiple trauma patients with mechanical ventilation. Crit Care 2011;15:424.

3. Kim DW, Jang JY, Shim H, Jung JY, Kim EY, Nam W, et al. Removal of aspirated teeth in a multiple trauma patient using fiberoptic bronchoscopy with simultaneous tracheostomy: Review of two cases. Respir Care 2014;59:e1-4.

\begin{tabular}{|l|l|}
\hline \multicolumn{2}{|c|}{ Access this article online } \\
\hline Quick Response Code: & Website: \\
\hline & www.jnaccjournal.org \\
\cline { 2 - 3 } & \\
\hline
\end{tabular}

